\title{
Influence of blend ratio on physical properties of oak tasar silk and acrylic blended spun yarn
}

\author{
Pallavi Lakhchaura* \\ Department of Clothing and Textiles, College of Home Science, G.B.P.U.A and T \\ Pantnagar, (Uttarakhand), India \\ Manisha Gahlot \\ Department of Clothing and Textiles, College of Home Science, G.B.P.U.A and T \\ Pantnagar, (Uttarakhand), India \\ Anita Rani \\ Department of Clothing and Textiles, College of Home Science, G.B.P.U.A and T \\ Pantnagar, (Uttarakhand), India \\ *Corresponding author. E-mail: pallavi.lakhchaura@gmail.com
}

\begin{abstract}
In this study an attempt was made to utilize the oak tasar silk spinning waste through blending it with acrylic fibre and prepared yarn in mechanised spinning system. The oak tasar silk and acrylic blended yarn were prepared on ring spinning machine with five different blend ratios viz. 100:0, 60:40, 50:50, 40:60 and 0:100. The prepared yarns were of medium to fine yarn count. Yarn Physical properties of yarns, unevenness and imperfections were studied and statistically analysed. Results revealed that the $100 \%$ acrylic and 50:50 tasar acrylic blended yarns had better properties as compared to 60:40 and 40:60. The addition of acrylic fibre content improved the physical properties, unevenness and imperfection of the blended yarns.
\end{abstract}

Keywords: Acrylic, Blending, Oak tasar, Ring Spinning, Spun yarn

\section{Article Info}

DOI:10.31018/jans.v11i2.2038

Received: March 10, 2019

Revised: May 17, 2019

Accepted: May 23, 2019

\section{How to Cite}

Lakhchaura, P. et al. (2019). Influence of blend ratio on physical properties of oak tasar silk and acrylic blended spun yarn. Journal of Applied and Natural Science, 11(2): 388- 393 https://doi.org/10.31018/ jans.v11i2.2038

\section{INTRODUCTION}

The basic objective of fibre blending is to assemble and combine together the correct proportion of components to meet aesthetic, performance such as fabric stability, abrasion resistance, moisture absorption and bulk and economic requirements in the end product. Yarns made from blends of different fibres are not superior in any one property like those produced from an individual fibre type instead they have combination of good properties which would be unattainable by using one type of fibre (Oxtoby, 1987). Blending gives the desirable characteristics to the end products as well as improves the spinning characteristics of short staple fibres by mixing of carrier fibres. Blending is also used to achieve different effects by varying colour of constituent fibres. The comfort factor conferred due to high moisture uptake in natural fibres can be intermingled with the performance factors such as abrasion resistance and dimensional stability of man- made fibres. These advantages also permit an increased variety of products to make and yield a strong marketing advantage.

Some studies have been done by the researchers on the blending of natural fibres (silk, wool, cotton) and man-made fibres (viscose, polyester, lyocell) to produce blended yarn fabrics of desired properties (Choudhuri et.al. 2013, Sreenivasa et.al. 2005). Oak tasar silk is a wild silk which has its unique properties like its golden brown colour, warmth and high moisture regain of $11.5 \%$. Silk wastes are comprised of entangled uneven length of fibres and uneven diameter. This unevenness affects the physical properties of developed yarns. The addition of manmade fibre would reduce the unevenness and improves the physical properties of blended yarn (Malik et al., 2012, Kilic and Okur, 2010). Being a manmade fibre acrylic has even staple length and diameter and is also known for its light weight, warmth, and bulk properties (NPTEL, 2012). Therefore, blending of oak tasar silk fibre with acrylic would contribute to towards the production of suitable blended yarn. In this study an attempt was made to blend oak tasar silk waste fibre with acrylic fibre to combine the natural brown colour, texture and high moisture regain properties of oak tasar silk with dimensional stability and easy care properties of acrylic fibres through ring spinning system.

\section{MATERIALS AND METHODS}

Materials: Acrylic fibre and oak tasar silk waste 
fibres have been used in the study. The basic fibre properties are given in Table 1 . The acrylic and oak tasar silk waste were procured from Pasupathi Acrylon Ltd. Kashipur, Uttarakhand and Appropriate Technology India, Ukhimath, Uttarakhand respectively. Oak tasar silk waste was collected in the form of entangled mass of long and short fibres. The staple length of acrylic fibres taken for the study was $51 \mathrm{~mm}$.

Methods: Three blended yarns were produced in the blended ratio of 60:40 Oak tasar/Acrylic, 50:50 Oak tasar/Acrylic and 40:60 Oak tasar/Acrylic. $100 \%$ acrylic and $100 \%$ Oak tasar silk yarn were also produced for base reference. All the prepared yarns were single. The blended and pure yarns were spun on ring spinning system. The Oak tasar silk waste was first passed through blow room for opening of waste than passed through carding machine. Thereafter the card slivers of oak tasar silk fibres were cut down at length of $51 \mathrm{~mm}$. Oak tasar staple cut fibres and acrylic fibres were hand mixed and then fed into the blow room to have an intimate and homogeneous blend. Thereafter, the materials were processed through card, draw frame, simplex and spun on a ring frame. These yarns were prepared at spinning pilot plant of Northern India Textile Research Association (NITRA), Ghaziabad.

Evaluation of physical properties of blended yarns: The prepared yarns were tested for different physical properties viz., yarn count, twist per inch, yarn strength, breaking elongation, yarn evenness, and yarn hairiness. A lea of 120 yards was made using wrap reel and weighed. Five readings were taken and their average was calculated. The yarn count ( $\mathrm{Ne}$ ) was calculated using following formula (Sahu and Goel, 2016):

Yarn count $(\mathrm{Ne})=64.8 /$ (Weight of a lea of 120 yards of yarn)

Eq........1

The twist per inch of the pure and blended yarn was measured by using digital twist tester (IS: 832 -1985). The twist per inch was displayed automatically on digital display of instrument. Ten reading were taken for each type of yarn and their mean was calculated. The Uster tensorapid automatic tensile tester was used to determine the tensile properties which include breaking force, tenacity, the breaking elongation and the breaking work of prepared yarns. Thirty observations were noted down for each type of yarn and their averages were taken. The evenness of the pure and blended yarn was determined by using Uster Tester- 5 S400 (D-1425-1996). Evenness of all pure and blended experimental yarns was measured in terms of Unevenness $(U) \%$, Mean square irregularity $(\mathrm{CVm} \%)$, thin places $(-40 \%$ and $-50 \%)$, thick places $(+35 \%$ and $+50 \%)$, and number of neps $(+200 \%$ and $+280 \%)$, hairiness value $(H)$ and standard deviation of hairiness value, five replications were taken for each type of yarn and their averages were taken.

Statistical analysis: Experimental data were analysed using SPSS (Version 1.6). Post hoc Tukey's test was used to compare mean at $5 \%$ level of significance.

\section{RESULTS}

Evaluation of physical properties of prepared blended yarns: Constructional details of prepared yarns are given in Table 1. Results of yarn properties like breaking force, tenacity, elongation and breaking work are presented in the Table 2.

Yarn count, TPI, twist direction: Yarn count of 100\% acrylic and 40: 60 oak tasar silk: acrylic blend was higher i.e. $28 \mathrm{~s} \mathrm{Ne}$, than the other blended yarns. The yarn count of 50:50 oak tasar: acrylic blend was 22s Ne whereas 60:40 oak tasar silk: acrylic blended yarn and $100 \%$ oak tasar silk yarn exhibited yarn count value of $25 \mathrm{~s} \mathrm{Ne}$. It was found that prepared yarns had yarn count in the range of $22 \mathrm{Ne}$ to $28 \mathrm{Ne}$ which were in the category of medium to fine yarn count. The $14 \mathrm{Ne}$ to $78 \mathrm{Ne}$ is considered as medium to fine yarn count range and largely used to make textiles for clothing and apparel. It was observed from the results that yarns having higher proportion of acrylic fibre were spun into finer yarn count.

Twists were given to impart cohesion to constituent fibres and strength to the yarn. Results reported in Table 2 reveals that TPI for $100 \%$ oak tasar silk, 100\% acrylic, 60:40, 50:50 and 40:60 oak tasar silk: acrylic were 17.34, 18.09, 18.15, 18.30 and 17.91 respectively. Statistically these values were at par to each other at 5\% significance level. The twist direction was $Z$ twist for all types of developed yarns.

Breaking force: Table 3 reveals that breaking force of $100 \%$ oak tasar silk yarn was lowest i.e. $294.3 \mathrm{gF}$ among other blend ratios. The 50:50 tasar: acrylic blend ratio had highest breaking force followed by $60: 40,0: 100$ and $40: 60$ blend ratios $(457.2,445.2,406.7$ and $348.35 \mathrm{gF}$ respectively). Statistically, values of breaking force for $60: 40,50: 50$ and 0:100 ratios showed no significant difference at $5 \%$ significance level. Coefficient of variation for breaking force of $100 \%$ oak tasar silk yarn indicated the highest variation i.e. $29.8 \%$ than $60: 40,50: 50,40: 60$ and 0:100 blended yarns.

It can be observed from the data that the addition of acrylic fibre with oak tasar silk waste fibre improved the yarn strength as compared to strength of $100 \%$ oak tasar silk (294.3gF). Basu (2001)

Table 1. Properties of Oak tasar silk and Acrylic fibres.

\begin{tabular}{lll}
\hline Fibre properties & Oak tasar silk & Acrylic \\
\hline Fineness (denier) & 3.03 & 1.23 \\
Tenacity (g/d) & 3.66 & 3.80 \\
Elongation (\%) & 23.25 & 36.00 \\
Moisture regain (\%) & 11.75 & 1.75 \\
\hline
\end{tabular}


Lakhchaura, P. et al. / J. Appl. \& Nat. Sci. 11(2): 388- 393 (2019)

Table 2. Constructional parameters of prepared blended yarns on the basis of blended ratio.

\begin{tabular}{lllll}
\hline S.N. & Blend Ratio (Oak tasar: Acrylic) & Yarn Count & Twist Per Inch (TPI) & Twist Direction \\
\hline 1 & $100: 0$ & 25 & $17.34^{\mathrm{a}}(10.08)$ & Z \\
2 & $60: 40$ & 25 & $18.15^{\mathrm{a}}(6.42)$ & $\mathrm{Z}$ \\
3 & $50: 50$ & 22 & $18.30^{\mathrm{a}}(6.55)$ & $\mathrm{Z}$ \\
4 & $40: 60$ & 28 & $17.91^{\mathrm{a}}(8.50)$ & $\mathrm{Z}$ \\
5 & $0: 100$ & 28 & $18.09^{\mathrm{a}}(6.98)$ & $\mathrm{Z}$ \\
\hline
\end{tabular}

Figures in parenthesis indicate coefficient of variation; Different symbols a b c d and e over the mean values indicates significant differences at $5 \%$ significance level.

Table 3. Physical properties of developed yarns with blended ratio.

\begin{tabular}{|c|c|c|c|c|c|}
\hline S.N. & $\begin{array}{ll}\text { Blend } & \text { Ratio } \\
\text { (Oak tasar: Acrylic) }\end{array}$ & Breaking force $\mathrm{gF}$ & Tenacity (g/d) & Elongation & $\begin{array}{l}\text { Breaking work } \\
\text { cN.cm }\end{array}$ \\
\hline 1 & $100: 0$ & $\begin{array}{l}293.4^{a} \\
(29.8)\end{array}$ & $\begin{array}{l}12.42^{\mathrm{a}} \\
(29.8)\end{array}$ & $\begin{array}{l}9.63^{\mathrm{a}} \\
(37.1)\end{array}$ & $\begin{array}{l}1057^{a} \\
(55)\end{array}$ \\
\hline 2 & $60: 40$ & $\begin{array}{l}445.6^{\mathrm{cd}} \\
(8.1)\end{array}$ & $\begin{array}{l}18.86^{\mathrm{C}} \\
(8.1)\end{array}$ & $\begin{array}{l}15.51^{b} \\
(10.9)\end{array}$ & $\begin{array}{l}2344^{c} \\
(16.6)\end{array}$ \\
\hline 3 & $50: 50$ & $\begin{array}{l}457.2^{d} \\
(13.7)\end{array}$ & $\begin{array}{l}16.86^{\mathrm{b}} \\
(13.7)\end{array}$ & $\begin{array}{l}15.21^{\mathrm{b}} \\
(17.1)\end{array}$ & $\begin{array}{l}2294^{c} \\
(27.0)\end{array}$ \\
\hline 4 & $40: 60$ & $\begin{array}{l}348.35^{b} \\
(10.25)\end{array}$ & $\begin{array}{l}16.31^{b} \\
(16.3)\end{array}$ & $\begin{array}{l}14.29^{b} \\
(22.8)\end{array}$ & $\begin{array}{l}1606^{b} \\
(29.8)\end{array}$ \\
\hline 5 & $0: 100$ & $\begin{array}{l}406.7^{c} \\
(8.8)\end{array}$ & $\begin{array}{l}19.10^{\mathrm{C}} \\
(8.8)\end{array}$ & $\begin{array}{l}18.84^{\mathrm{C}} \\
(11.3)\end{array}$ & $\begin{array}{l}2478^{c} \\
(16.3)\end{array}$ \\
\hline
\end{tabular}

Figures in parenthesis indicate coefficient of variation; Different symbols a b c d and e over the mean values indicates significant differences at $5 \%$ significance level.

also stated that the breaking force of yarn would be higher for long fibres content and lower for short fibres content in the yarn. Therefore with the addition of acrylic fibres reduced the proportions of short fibres of oak tasar from the yarn which resulted in improved breaking strength. The reduction of CV\% value of breaking force with the addition of acrylic fibre could be due to the addition of even length of acrylic fibres which reduced variability in breaking force of yarns.

Tenacity: Tenacity defines the specific strength relative to yarn linear density. Table 2 shows the results of tenacity of developed yarns. Tenacity value of $60: 40$ blend ratios was $18.86 \mathrm{~g} / \mathrm{d}$ which is statistically at par to the tenacity of $100 \%$ acrylic yarn at $5 \%$ significance level. The tenacity of $100 \%$ acrylic showed highest value i.e. $19.10 \mathrm{~g} / \mathrm{d}$ among the developed yarns. The 50:50 and 40:60 blends had statistically comparable tenacity values of 16.86 and $16.31 \mathrm{~g} / \mathrm{d}$ respectively. The values of tenacity of $50: 50$ and $40: 60$ blend was better than the $100 \%$ oak tasar silk yarn. The 100 $\%$ oak tasar silk yarn had lowest value of tenacity $(12.42 \mathrm{~g} / \mathrm{d})$. The higher tenacity value of $100 \%$ acrylic yarn may be due to the even length of fibres in the yarn structure along with the higher tenacity value of acrylic fibre as compared to oak tasar silk waste fibre. Choudhuri et al. (2013) observed reduction in tenacity value by increasing eri silk content in the eri/acrylic blended yarn due to presence of more number of weaker fibres.

It can be inferred from the results that with the addition of acrylic fibre, yarn tenacity values were found to be increased. Due to more length variability in oak tasar silk waste fibres value of $\mathrm{CV} \%$ was highest in case of $100 \%$ oak tasar silk waste (29.8\%) than the CV\% of other developed yarns.

Elongation: It is clear from Table 2 that least elongation value $(9.63 \%)$ was found for the $100 \%$ oak tasar silk yarn and whereas $100 \%$ acrylic yarn exhibited highest elongation value (18.84\%). Significant difference $(p<0.05)$ was found between the elongation values of $100 \%$ oak tasar yarn and $100 \%$ acrylic yarn. The elongation values of $60: 40$, 50:50 and 40:60 blend ratios were 15.51, 15.21 and $14.29 \%$ respectively. Statistical analysis showed no significant difference $(p>0.05)$ among the elongation values of $60: 40,50: 50$ and $40: 60$ blend ratios.

Lowest elongation of $100 \%$ oak tasar yarn and highest elongation of $100 \%$ acrylic yarn may be due to the low elongation of oak tasar fibre as compared to acrylic fibre. Thilagaathi and Karthik (2016) reported that the fibre elongation influenced most to the yarn elongation property. Chaudhari et al. (2013) studied the breaking elongation of eri and acrylic blended yarns and also observed that breaking elongation was decreased with increase in eri $\%$ in the blend which may be due to less elongation of eri silk as compared to acrylic fibre. It can also be observed from the results that addition of acrylic fibre with oak tasar silk waste fibre increased the elongation of blended yarns as compared to $9.63 \%$ for $100 \%$ oak tasar silk yarns.

Breaking work: It is a measure of energy required to break the yarn. It is the ultimate performance of the yarn during post spinning operations like winding, warping and weaving (Basu,2001). Table 3 displays the values of breaking work of different blend ratios. Breaking work for $60: 40,50: 50$ and 


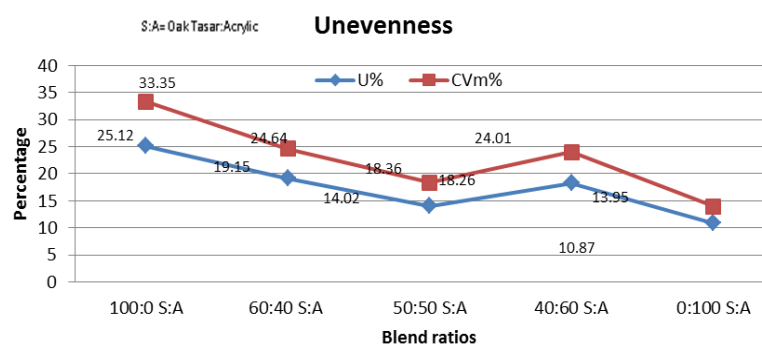

Fig. 1. Unevenness ( $U \%$ and $\mathrm{CVm} \%$ ) of prepared blended yarns.

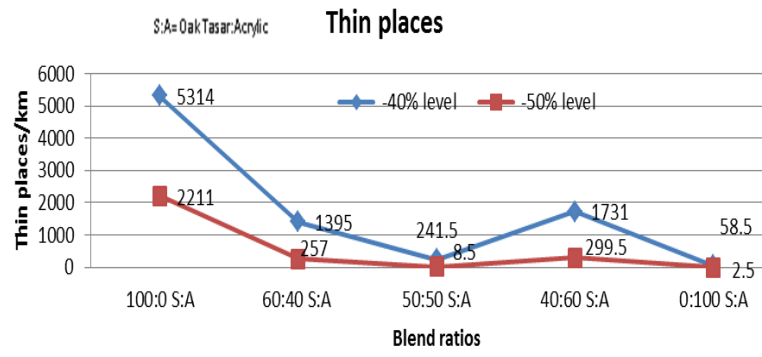

Fig. 2. Thin places $/ \mathrm{km}$ of prepared blended yarns at $-40 \%$ and $-50 \%$ levels.

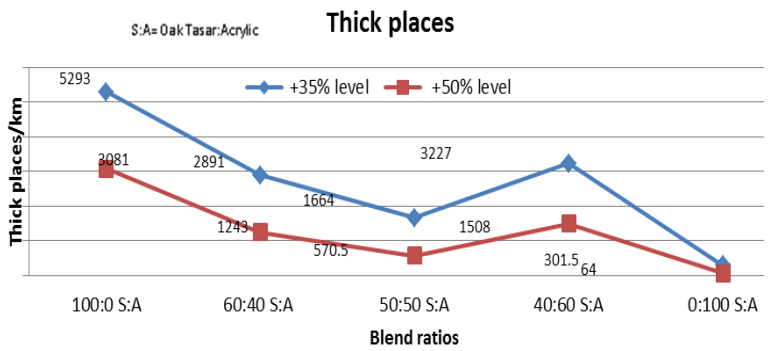

Fig 3. Thick places $/ \mathrm{km}$ of prepared blended yarns at $+35 \%$ and $+50 \%$ levels.

40:60 were 2344, 2294 and $1606 \mathrm{cN} . \mathrm{cm}$ respectively. The breaking work value of $60: 40$ and $50: 50$ blends was statistically at par to $100 \%$ acrylic yarn at $5 \%$ significance level. The breaking work value of 40:60 blend was higher as compared to $100 \%$ oak tasar silk yarn. The breaking work value was highest for $100 \%$ acrylic yarn $(2478 \mathrm{cN} . \mathrm{cm})$ and lowest for $100 \%$ oak tasar silk yarn $(1057 \mathrm{cN} . \mathrm{cm})$. The coefficient of variation was found to be the highest $(55 \%)$ in case of $100 \%$ oak tasar silk yarn and lowest $(16.3 \%)$ in case of $100 \%$ acrylic yarn. Statistical analysis showed that values of breaking work of $60: 40$, 50:50 and 0:100 blended yarns showed no significant difference whereas, a significant difference was observed between breaking work of $100 \%$ oak tasar and 40:60 blended yarns at 5\% significance level.

It can be inferred from the data that addition of acrylic improved the breaking work of yarns. However the low breaking work of 40:60 blends may be because of combined effect of high variation in fibre length and finer yarn count of 40:60 blended yarn as compared $60: 40$ and $50: 50$ blended yarns.

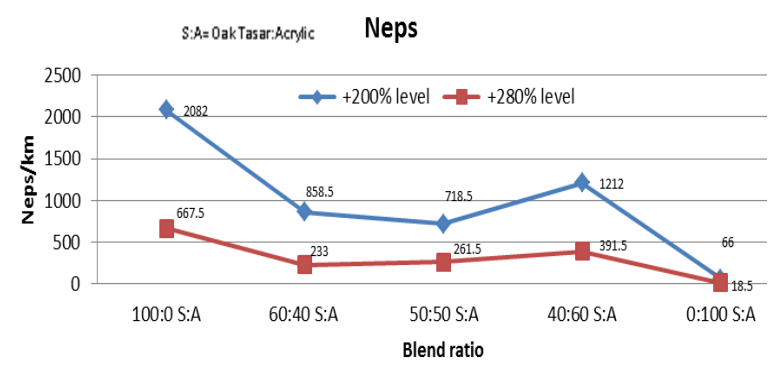

Fig 4. Neps $/ \mathrm{km}$ of prepared blended yarns at $+200 \%$ and $+280 \%$ levels.

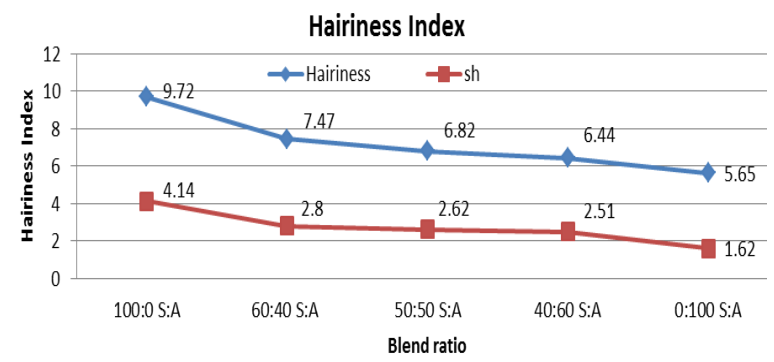

Fig 5. Hairiness Index and sh values of prepared blended yarn.

Evaluation of yarn unevenness and imperfections of prepared blended yarns: The results include $\mathrm{U} \%, \mathrm{CVm} \%$, thin $-40 \% / \mathrm{km}$, thin $-50 \% / \mathrm{km}$, thick $+35 \% / \mathrm{km}$, thick $+50 \% / \mathrm{km}$, neps $+200 \%$, neps $+280 \%$ and hairiness index.

Unevenness (U \%) and Mean square irregularity $(\mathbf{C V m} \%)$ : It can be observed from the Fig. 1 that unevenness percent was highest $(25.12 \%)$ for $100 \%$ oak tasar silk yarn and lowest $(10.87 \%)$ for $100 \%$ acrylic yarn. The Unevenness $\%$ for $60: 40$, $50: 50$ and $40: 60$ were $19.15 \%, 14.02 \%$ and $18.26 \%$ respectively. From the statistical analysis it was found that, values of unevenness percent for 60:40 and 40:60 oak tasar silk: acrylic blend ratios showed no significant difference. Similarly, unevenness percent values for $50: 50$ and 0:100 oak tasar silk: acrylic blend showed no significant difference at $5 \%$ significance level.

This may be due to the higher fibre length as well as diameter variations of oak tasar silk waste fibre, whereas acrylic, being a synthetic fibre has the same cross section throughout the length and also lower fibre length variation. As variation in fibre diameter and length variation is one of the major reasons for yarn unevenness, addition of acrylic fibre with oak tasar silk waste fibre reduced the unevenness percent for all blended yarns.

The coefficient of variation of unevenness ( $\mathrm{CVm}$ $\%$ ), is more acceptable measurement of yarn evenness than $U \%$. Similar pattern was observed as for $\mathrm{U} \%, \mathrm{CVm} \%$ was reduced by adding acrylic fibre with the oak tasar silk waste fibre in blends. It was found that $100 \%$ oak tasar silk yarn (33.35 $\%$ ) had highest $\mathrm{CVm} \%$ value. The lowest value of CVm \% was obtained for $100 \%$ acrylic yarn (13.95\%). CVm \% for 60:40 (24.64\%) and 40:60 
$(24.01 \%)$ blend ratio showed no significant difference at $5 \%$ significance level. Similarly, it was found that values for 50:50 blend and $100 \%$ acrylic yarn showed no significant difference at 5 $\%$ significance level.

Thin places: Thin places were measured at two different sensitivity levels $(-40 \%$ and $-50 \%)$. It can be seen from the Fig. 2 that the thin places at $40 \%$ sensitivity level was lowest for 0:100 (58.5/ $\mathrm{km})$ followed by 50:50 (241.5/km), 60:40 (1398/ $\mathrm{km}), 40: 60(1731 / \mathrm{km})$ and 100:0 (5314/km) oak tasar silk and acrylic blended yarns. It can be observed from the results that $100 \%$ silk had maximum number of thin places and the addition of acrylic fibre reduced thin places tremendously. Statistically, values for $60: 40$ and 50:50 blended yarn showed no significant difference at $5 \%$ significance level. Significant difference was observed among 0:100, 40:60 and 100:0 blended yarns.

At $-50 \%$ sensitivity level, a reduction was found in values of thin places for all blend ratios when compared to $-40 \%$ sensitivity levels. Lowest value was observed for $100 \%$ acrylic yarn $(2.5 / \mathrm{km})$ followed by $50: 50(8.5 / \mathrm{km}), 60: 40(257 / \mathrm{km}), 40: 60$ $(299.5 / \mathrm{km})$ and 100:0 (2211/km). Tukey test described that there was a significant difference in the value of $100 \%$ oak tasar silk yarn and all other ratios of blended yarns. Whereas values of thin places at $-50 \%$ sensitivity level for $0: 100,40: 60$, 50:50 and 60:40 showed no significant difference at $5 \%$ significance level, although the values showed differences among them.

Thick places: Thick places were measured at $+35 \%$ and $+50 \%$ sensitivity levels. It can be seen from the Fig. 3 that at $+35 \%$ level highest thick places were found for $100 \%$ oak tasar silk yarn $(5293 / \mathrm{km})$ and lowest for $100 \%$ acrylic yarn $(301.5 / \mathrm{km})$. Tukey test was used for analyzing significant difference among thick places of developed yarns. It was found that at $+35 \%$ level the values of thick places showed no significant difference $(p>0.05)$ for $60: 40(2891 / \mathrm{km})$ and $40: 60$ $(3227 / \mathrm{km})$ blend ratios, whereas a significant difference $(p<0.05)$ was observed among 100:0 (5293/km), 50:50 (1664/km) and 0:100 (301.5/km) blend ratios.

Similarly, at +50 sensitivity level highest thick places were found for $100 \%$ oak tasar silk yarn $(3081 / \mathrm{km})$ and lowest for $100 \%$ acrylic yarn $(64 /$ $\mathrm{km})$. No significant difference was found between values of thick places for $60: 40(1243 / \mathrm{km})$ and $50: 50(570.5 / \mathrm{km})$ blend ratios at $5 \%$ significance level. Likewise, values of thick places at $+50 \%$ level for 60:40 $(1243 / \mathrm{km})$ and 40:60 (1503/km) blend ratios showed no significant difference at 5 $\%$ significance level. It was found that there was a significant difference between 100:0 blend ratios and with all other blend ratios $(60: 40,50: 50$, 40:60, 0:100 oak tasar: acrylic). Gahlot and Pant (2011) studied the thick places of oak tasar and viscose blended yarns and found significant reduction in thick places with the addition of viscose fibre in the blends.

For both $+35 \%$ and $+50 \%$ levels, highest thick places were found in $100 \%$ oak tasar silk yarn and lowest in $100 \%$ acrylic yarn. At both the sensitivity levels, it was observed that thick places were reduced by the addition of acrylic fibre with oak tasar silk fibre in blended yarns.

Neps: Neps were measured at $+200 \%$ and $+280 \%$ levels. The neps per kilometre for $50: 50$, $60: 40$ and $40: 60$ blend ratios were $718.5 / \mathrm{km}$, $858.5 / \mathrm{km}$, and $1212 / \mathrm{km}$ respectively as compared to $66 / \mathrm{km}$ for $100 \%$ acrylic yarn and 2082 for $100 \%$ silk yarn which can be seen in Fig. 4 . Statistically neps at $+200 \%$ level for $60: 40,50: 50$ and 40:60 blended yarns showed no significant difference at $5 \%$ significance level. Whereas, significantly high neps were observed on $100 \%$ oak tasar silk yarn.

Similarly at +280 level, $100 \%$ acrylic yarn exhibited lowest neps $(18.5 / \mathrm{km})$ whereas $100 \%$ oak tasar silk yarn exhibited maximum $(667.5 / \mathrm{km})$ neps per kilometre. The amount of neps per kilometre were reduced tremendously as compared to $+200 \%$ level which represents that at $+280 \%$ level number of neps/km observed were less. The values of neps for 60:40 (233/km), 50:50 (261.5/ $\mathrm{km})$ and 40:60 (391.5/km) blended yarns also showed no significant difference at $5 \%$ significance level.

It was observed that neps per kilometre of yarn at both levels reduced by the addition of acrylic content with the oak tasar silk waste fibres in developed blended yarns. There is strong relationship between neps in yarn and neps in raw material which means more neps in the raw material results in more neps (Fruter, 2009). As silk waste was used in this study, which contained neps of improperly degummed cocoons therefore blended yarns with higher silk content showed more neps/ $\mathrm{km}$.

Hairiness $(\mathbf{H})$ : Hairiness values measured in the yarn indicate the amount of short fibres and variation in the fibre length, since the majority of the protruding hairs are contributed by the short fibres (Saravanan and Kumar, 2009). Highest hairiness value was observed for 100:0 (9.72) followed by $60: 40$ (7.47), 50:50 (6.82), 40:60 (6.44) and 0:100 (5.65) blend ratios. Statistically, hairiness values for all blended yarns were significantly different at $5 \%$ significance level, different notations are representing difference among them. It was seen from the Fig. 5 that on reducing the oak tasar silk waste fibre in the blend ratios hairiness values decreased significantly. Gahlot and Pant (2011) also found the reduction in the hairiness value with decreasing oak tasar silk content in silk and viscose blended yarns This may be due to the waste characteristics of oak silk fibre used for yarn 
development fibres. The sh value indicates standard deviation for the hairiness values; same trend as in case of hairiness index was observed for sh values of all developed yarns.

\section{Conclusion}

It can be concluded that the addition of acrylic fibres with the oak tasar silk waste improved the physical properties of the blended yarn. With the addition of acrylic fibre in the blends breaking force of yarns was improved. The 50:50 blend ratio showed highest breaking force among other blend ratios and $100 \%$ oak tasar yarn exhibited lowest breaking force value. The tenacity, elongation and breaking work values were found to be highest for $100 \%$ acrylic yarn and lowest for 100 $\%$ silk yarn. It can also be observed from the results that with addition of acrylic fibres with oak tasar waste the tenacity, elongation and breaking work values were found to be increased. The $U \%$ and $\mathrm{CVm} \%$ values were improved with addition of acrylic fibres with oak tasar waste in the blend. The highest unevenness and imperfections were exhibited by $100 \%$ oak tasar yarn and lowest by $100 \%$ acrylic yarns. The 50:50 blended yarn exhibited less $\mathrm{U} \%$ and $\mathrm{CVm} \%$ as compared to 60 : 40 and 40:60 oak tasar: acrylic blended yarns. The 50:50 blended yarn exhibited less yarn imperfections compared to $60: 40$ and 40:60 oak tasar: acrylic blended yarns. Yarn imperfections were improved with the addition of acrylic fibres with oak tasar waste in the blend. Yarn hairiness was improved on increasing the acrylic content in the blends. The highest hairiness value was exhibited by $100 \%$ oak tasar yarn and lowest value for 100 $\%$ acrylic yarn. The 40:60 blended yarn showed less hairiness compared to 60 : 40 and 50:50 oak tasar: acrylic blended yarns.

\section{REFERENCES}

1. Basu A, (2001). Textile testing: Fibre, yarn and fabric. Coimbatore, The South India Textile Research
Association, $381 \mathrm{p}$

2. Choudhuri, P. K., Majumdar, P. K. and Sarkar, B. (2013). Studies on Tensile Properties of eri/acrylic blended yarn. Indian Journal of Fibre and Textile Research, 38, 66-73.

3. Fruter R., (2009). Physical properties of spun yarn. Standards from fibre to fabric. 3: 1-36. from http:// quantumclearer.com/fileadmin/customer/Knowledge/ Textil e_Kno wHow/Yarn_ testing/AR_Physical properties_of_sun_yarns_01.pdf on 13, December, 2017

4. Gahlot and Pant (2011) Properties of oak tasar/ viscose blended yarns. Indian Journal of Fibre and Textile Resesarch 36, 187-189.

5. Kilic M and Okur A (2010) The properties of cottonTencel and cotton-Promodal blended yarns spun in different spinning systems. Textile Research Journal, 80(10): 156-172

6. Malik S A Tanwari A, Syed U, Qureshi R F and Mengal N (2012) Blended yarn analysis: part i-influence of blend ratio and break draft on mass variation, hairiness, and physical properties of 15 tex pes/co blended ring-spun yarn, Journal of Natural Fibers, 9:3, 197 -206, DOI: 10.1080/15440478.2012.706446

7. NPTEL (2012) Synthetic fibres Retrieved from https:// nptel.ac.in/courses/116102026/synthetic\%20fibersm7/acrylic.htm on 10, April, 2019

8. Oxtoby E, (1987) Spun Yarn Technology. Oxford, Butterworth and Co Ltd., 250.

9. Sahu and Goel (2016) Properties of stretchable cover spun yarns developed from lyocell and spandex. International Journal Of Engineering Sciences \& Research Technology. 5 (12):383-388.

10.Saravanan D and Kumar S S, (2009) A novel approach to process cotton/long staple fibre blends on short staple ring frame. Indian J Fibre and Tex Res, 34(3): 47-51

11.Sreenivasa A, Itagi M R, Kumar H L V and Nadiger G S, (2005) Development and study of the properties of eri silk and polyester blended yarn. Retrieved from https://www.researchgate.net/publication/2929 14072 _Development_and_study_of_the_properties_of_Eri_ silk_and_polyester_blended_yarn on 12, April 2019

12. Thilagaathi G and Karthik T (2016), Process control and quality control in spinning. Florida, CRC Press, 422 